\title{
Coping Strategies and their Association with Diabetes Emotional Distress, Depression and Diabetes Self-Care among People living with Diabetes in Zambia
}

Given Hapunda ( $\sim$ given.hapunda@unza.zm )

University of Zambia

\section{Research Article}

Keywords: coping strategies, diabetes emotional distress, depressive symptoms, diabetes self-care, Type 1 and Type 2 diabetes

Posted Date: February 28th, 2022

DOl: https://doi.org/10.21203/rs.3.rs-1363090/v1

License: (c) This work is licensed under a Creative Commons Attribution 4.0 International License. Read Full License 


\section{Abstract \\ Background}

Utilising coping strategies to reduce and manage the intensity of negative and distressing emotions caused by diabetes is essential. However, little is known about the use of coping strategies among people living with diabetes in Sub-Saharan African countries like Zambia. This study investigates coping strategies used by people with diabetes in Zambia and how these are associated with diabetes-specific emotional distress, depression and diabetes self-care.

\section{Methods}

Cross-sectional data from 157 people with diabetes were collected. Coping styles were measured using the Brief COPE, distress using the Problem Areas in Diabetes, depression using the Major Depression Inventory and self-care using the Diabetes Self-Care scale.

\section{Results}

Data showed that adaptive coping strategies were the most frequently used coping strategies among Zambian individuals with diabetes. Maladaptive coping strategies were related to increased diabetes distress and depression. Emotional support was related to better diabetes self-care, while self-blame was related to poor diabetes self-care.

\section{Conclusion}

There is a need to help individuals with diabetes identify adaptive strategies that work best for them in order to improve their quality of life.

\section{Background}

Diabetes self-care can be very complex, challenging and stressful [1, 2], especially in developing countries where health care and formal support systems are still underdeveloped [3]. Daily self-management involves frequent blood glucose monitoring and insulin adjustments and administration, engaging in physical activities, consideration of nutrition, managing sleep duration and blood glucose level. In addition to the medical, social, financial demands of optimal daily self-management, emotional problems are common and contribute to the overall burden of living with diabetes $[4,5]$. Therefore, the goal for the treatment of diabetes is to prevent acute and chronic complications while preserving a better quality of life and psychological well-being [6].

Diabetes specific psychosocial challenges are prevalent in people living with diabetes (PWD) $[7,8]$. For instance, a systematic review showed that the prevalence rate of depression is more than three times higher in people with type 1 diabetes (12\%, range $5.8-43.3 \%$ vs 3.2\%, range $2.7-11.4 \%)$ and nearly twice as high in people with type 2 diabetes (19.1\%, range $6.5-33 \%$ vs $10.7 \%$, range $3.8-19.4 \%$ ) compared to those without [9]. Further, anxiety and disease-related distress are known to be problematic for PWD [7]. In Zambia, levels of diabetes-specific distress and depressive symptoms have been reported among type 1 or type 2 diabetes in Zambia [10]. On its own, diabetes 
can be an unpredictable and stressful disease [7]. Diabetes is complex to manage, and comorbid conditions such as hypoglycaemia or hyperglycaemia and chronic diseases such as neuropathy, nephropathy and retinopathy are common, hence the need to find optimal ways to manage the condition $[4,11]$. Such conditions negatively affect the quality of life of diabetes people. Already, evidence in Zambia shows that healthy controls (22.42 vs 18.58) had higher scores on life satisfaction than young people with type 1 diabetes [12]. To help people with diabetes maintain equilibrium, adaptive coping strategies are important. Adaptive coping strategies can help maintain good health outcomes, such as glycaemic control [13]. In contrast, maladaptive strategies such as wishful thinking and avoidant can affect metabolic control and psychosocial outcomes such as quality of life and depressive symptoms $[7,13,14]$.

Data from a 14-country study with about 10 countries sampled from low- and middle-income countries (LMICs), of which two (Uganda and Kenya) were from SSA, showed that in many of these LMICs, diabetes care was not comprehensive. Most services lacked appropriate identification and care processes for psychological and psychiatric problems [15]. This is because, in developing countries, the medical care value chain does not include mental health specialists due to a shortage of such expertise. Yet, diabetes and psychological conditions go handin-hand, and the bi-directional nature of diabetes and psychosocial issues entails that if service care providers simultaneously care for psychological well-being and medical outcomes, their patients' outcomes will also get better [16]. Despite this evidence in Sub Saharan African, little is known on the use of coping strategies in individuals with diabetes. Thus, coping strategies remain an important study area, especially in developing countries with unique social-cultural factors, suboptimal diabetes care and management systems.

A stressor's effect on a person is based on that person's feeling of threat, vulnerability, and ability to cope than the stressful event itself [17]. How one manages the stressor can be adaptive or maladaptive. Coping is maladaptive when an individual applies techniques that are not adjusting adequately or appropriately to a situation or stress that requires one to manage [18]. Greater engagement in maladaptive coping is associated with anxiety, depressive symptoms and poorer quality of life $[19,20]$. Evidence from qualitative data among Zambian adolescents with type 1 diabetes showed young people used maladaptive coping strategies such as avoidance, for example, avoiding injecting themselves insulin was common [21]. The problem-focused and the emotional focused coping strategies are the two common types of personal coping strategies. The problem-focused coping strategies are aimed at changing the source of stress, while emotional focused are oriented towards managing the emotions that accompany the perceived stressor. Both are effective in making the stressed individual feel better but are not equally effective in managing stress. In diabetes, individuals with emotion-focused, social-support focused and problem-focused coping have higher levels of positive diabetes self-care activities while patients with avoidancefocused coping had negative diabetes self-care activities [13]. Although some emotional and behavioural strategies are considered maladaptive, in situations where the stressor is unavoidable, such as diabetes self-care, maladaptive strategies, whether emotional or behavioural, can be an option [22]. For instance, distraction and religion as coping strategies do not remove the stressor but contribute to higher wellbeing and positive emotions [22]. Still, it can be helpful in diabetes as it empowers an individual and can lead to finding meaning and purpose in disorder. In light of the Brief Coping Orientation to Problems Experienced (Brief-COPE), the primary tool of this study, planning, active coping, positive reframing, acceptance, are among those considered adaptive coping strategies. Self-distraction, denial, behavioural disengagement, venting, humour, self-blame and substance use are examples of maladaptive coping strategies [23].

\section{Methods}




\section{Study aim}

Therefore, this study aimed to identify which coping strategies are used by Zambian PWD and examine how these strategies are associated with diabetes-specific distress, depression, and diabetes self-care activities.

\section{Design}

A cross-sectional study was conducted among outpatient individuals with type 1 or 2 diabetes mellitus.

Participants were from four major hospitals in Zambia, with different age groups and socioeconomic backgrounds.

\section{Participants and sites}

The study participants were drawn from four major hospitals in Zambia, namely Lusaka 48 (31\%), Kitwe 60 (38\%), Ndola 35 (22\%) and Livingstone 14 (9\%). One hundred and fifty-seven (157) respondents, of which 93 (59\%) had type 1 diabetes mellitus, 80 (51\%) females, and 42 (27\%) were adolescents according to WHO definition. The average age of the respondents was $39 \pm 17$ years. See Table 1 for the demographic characteristics of the study sample. Purposive sampling was used to recruit respondents as long as they met the inclusion criteria of being at least 12 years or older, having been diagnosed with diabetes for at least six months, using oral medication or insulin therapy. Data was collected from these four city hospitals over one year.

Table 1: Demographic and clinical characteristics of 157 participants with type 1 and type 2 diabetes

\begin{tabular}{ll} 
Sex, $n(\%)$ & \\
Females & $80(51 \%)$ \\
Age, mean (SD) & $39 \pm 17$ \\
Age range & $12-68$ years \\
Location of patients & $48(31 \%)$ \\
Lusaka & $60(38 \%)$ \\
Kitwe & $35(22 \%)$ \\
Ndola & $14(9 \%)$ \\
Livingstone & \\
Age Category $n(\%)$ & $42(27 \%)$ \\
Adolescents & $115(73 \%)$ \\
Adults & \\
Educational levels $n(\%)$ & $14(31 \%)$ \\
Adolescents (42) & $16(38 \%)$ \\
$5-7$ Grade (Primary school) & $14(31 \%)$ \\
8-12 Grade (Secondary school) & \\
Missing & \\
Adults (115) & $10(9 \%)$ \\
Primary education & $29(25 \%)$ \\
Secondary education & $22(19 \%)$ \\
Tertiary education & $54(47 \%)$ \\
Missing & $6(5 \%)$ \\
Marital status (Adults 115$) n(\%)$ & $80(70 \%)$ \\
Single & $29(25 \%)$ \\
Married & \\
Missing & $93(59)$ \\
Type of diabetes & $58(37)$ \\
Type 1 & $6(4)$ \\
Type 2 & \\
Missing (either type 1or 2) & $25(5) \mathrm{kg} / \mathrm{m}^{2}$ \\
Man (SD) & $25(5) \mathrm{kg} / \mathrm{m}^{2}$ \\
Females & $26(5) \mathrm{kg} / \mathrm{m}^{2}$ \\
Adolescents & $22(4) \mathrm{kg} / \mathrm{m}^{2}$ \\
Adults & $27(5) \mathrm{kg} / \mathrm{m}^{2} 2$ \\
\hline
\end{tabular}

\section{Instruments}


Generic coping strategies (not diabetes-specific) were assessed using the brief COPE. The brief COPE is a short version of the COPE developed by Carver, Scheiver \& Weinbraub [23]. The 28 items self-report scale assesses coping styles or strategies on two main dimensions - problems focused and emotional focused coping styles. The scale consists of 14 domains/subscales (self-distraction, active coping, denial, substance use, use of emotional support, use of instrumental support, behavioural disengagement, venting, positive reframing, planning, humour, acceptance, religion, self-blame) of two items each. Participants respond to statements on a four Likert scale ( 1 = I have not been doing this, to $4=I$ have been doing this). Higher scores indicate greater use of a particular coping strategy. The full scale has a good Cronbach' alpha of 0.84 [23]. In the current study, Cronbach alphas were 0.81 , and Lambda 2 was 0.82 . The two-item based 14 sub-scales have previously been documented to have notoriously low reliabilities [24,25]. In the current study, internal consistency was low, ranging for most scales .34-71. Alpha for subscales was as follows: self-distraction $=.42$; active coping $=.56$; denial $=.52$; substance use $=.71$; use of emotional support .46; use of instrumental support $=.55$; behavioural disengagement $=.34$; venting $=.40$; positive reframing $=.50 ;$ planning $=.54$; humour $=54$; acceptance $=.48$; religion $=.59$; self-blame $=.34$.

Diabetes-specific emotional distress was assessed using the Problem Areas in Diabetes (PAID). The PAID is a 20item self-report measure used to assess diabetes-specific emotional distress, including a range of feelings such as diabetes-related anger, fear, depression, worry and guilt. Items can be responded to on a scale from 0 (not a problem) to 4 (serious problem). An overall score for the PAID can be calculated by adding all of the item scores and multiplying them by 1.25 , which gives a total score ranging from $0-100$. Higher scores indicate more distress. Reported Cronbach's alphas for the PAID ranges from 0.84 to $0.96[26,27]$.In the current study the alpha was 0.88 $($ Lambda2 $=0.89)$.

Diabetes Self-care was assessed using the Self-Care Inventory. The 13 item Self-Care Inventory (SCI) is a self-report measure used to assess people' perceptions of their adherence to diabetes self-care recommendations over the past month. Individuals rate themselves on a 5-point Likert scale that reflects how well they followed recommendations for self-care during the past month (i.e., 1 = "never do it" to 5 = "always do this as recommended, without fail"). Higher scores indicate more optimal diabetes self-care [28]. Cronbach's alpha for the SCI was 0.84 (Lambda2 $=0.85)$ for T1DM and 0.85 (lambda2 = 0.86) for T2DM.

Depression was assessed using the Major Depression Inventory (MDI). The MDI is a 12-item self-report questionnaire used to assess depression. Items of the MDI ask individuals to rate how long in the past two weeks each of the depressive symptoms was present on a six-point scale ranging from 0 "not at all" to 5 "all time. Therefore, a higher score indicates the presence of depressive symptoms. It can be used as an instrument measuring the severity of depression with a range from $0-60$. In previous studies, the MDI had excellent internal consistency with Cronbach alphas ranging from 0.89 to $0.94[29,30]$. In the current study Cronbach alpha was 0.80 $($ Lambda2 $=0.81)$.

\section{Data analysis}

Descriptive statistics involving means (standard deviation) and frequency percentages were computed to identify the coping strategies frequently used by people in this study. Coping strategies used $50 \%$ or more were considered frequently (commonly) used. An independent $t$-test was computed to test whether the use of coping strategies differed between males versus females, type 1 versus type 2 diabetes, adolescents versus adults. Further, Pearson Product correlation was used to examine the association between coping strategies, diabetes-specific emotional- 
distress, depression and diabetes self-care. All analysis was done in IBM SPSS version 23. Statistical significance was set at $p<0.05$.

\section{Results}

The most frequently used coping strategies among Zambian individuals with diabetes are presented in Table 2. In general, adaptive coping strategies (67\% religious coping; $58 \%$ acceptance, $57 \%$ seeking instrumental support and $56 \%$ using active coping) were commonly used among Zambian individuals with diabetes. For details on strategies applied by males and females with type 1 and type 2, see Table 3.

Table 2

Proportion of individuals with diabetes using each of the fourteen coping strategies

\begin{tabular}{|c|c|c|c|c|c|c|c|}
\hline \multirow[t]{2}{*}{ Coping strategy } & \multirow[b]{2}{*}{ All types } & \multicolumn{2}{|c|}{ Type of Diabetes } & \multicolumn{2}{|l|}{ Age Category } & \multicolumn{2}{|l|}{ Sex } \\
\hline & & Type 1 & Type 2 & Adolescents & Adults & Males & Females \\
\hline \multicolumn{8}{|c|}{ Adaptative coping strategies } \\
\hline Active coping & $84(56 \%)$ & $47(53 \%)$ & $34(62 \%)$ & $15(38 \%)$ & $69(63 \%)$ & $43(61 \%)$ & $40(52 \%)$ \\
\hline Emotional use & $70(46 \%)$ & $36(40 \%)$ & $31(53 \%)$ & $16(41 \%)$ & $54(48 \%)$ & $40(53 \%)$ & $30(39 \%)$ \\
\hline Instrumental use & $87(57 \%)$ & $47(52 \%)$ & $36(63 \%)$ & $20(50 \%)$ & $67(60 \%)$ & $40(53 \%)$ & $47(62 \%)$ \\
\hline Positive reframing & $52(34 \%)$ & $28(32 \%)$ & $21(36 \%)$ & $7(18 \%)$ & $45(40 \%)$ & $29(38 \%)$ & $13(31 \%)$ \\
\hline Planning & $69(47 \%)$ & $36(42 \%)$ & $30(53 \%)$ & $10(29 \%)$ & $59(52 \%)$ & $38(69 \%)$ & $30(40 \%)$ \\
\hline Acceptance & $85(58 \%)$ & $50(59 \%)$ & $41(56 \%)$ & $23(64 \%)$ & $62(56 \%)$ & $43(60 \%)$ & $41(56 \%)$ \\
\hline Religion & $101(66 \%)$ & $56(62 \%)$ & $41(71 \%)$ & $21(53 \%)$ & $80(70 \%)$ & $49(64 \%)$ & $51(66 \%)$ \\
\hline \multicolumn{8}{|c|}{ Maladaptive coping strategies } \\
\hline Self-blame & $12(8 \%)$ & $9(10 \%)$ & $6(10 \%)$ & $6(11 \%)$ & $6(5 \%)$ & $3(4 \%)$ & $8(10 \%)$ \\
\hline Self-distraction & $49(33 \%)$ & $28(32 \%)$ & $21(37 \%)$ & $12(31 \%)$ & $37(34 \%)$ & $23(31 \%)$ & $26(34 \%)$ \\
\hline Denial & $27(18 \%)$ & $13(14 \%)$ & $13(22 \%)$ & $5(12 \%)$ & $22(19 \%)$ & $12(16 \%)$ & $5(19 \%)$ \\
\hline Substance use & $5(3 \%)$ & $3(3 \%)$ & $2(3 \%)$ & $2(5 \%)$ & $3((3 \%)$ & $4(5 \%)$ & $1(1 \%)$ \\
\hline $\begin{array}{l}\text { Behavioural } \\
\text { disengagement }\end{array}$ & $27(18 \%)$ & $16(18 \%)$ & $11(20 \%)$ & $5(13 \%)$ & $22(20 \%)$ & $17(24 \%)$ & $10(13 \%)$ \\
\hline Venting & $27(19 \%)$ & $19(22 \%)$ & $8(15 \%)$ & $11(28 \%)$ & $16(15 \%)$ & $9(13 \%)$ & $18(25 \%)$ \\
\hline Humour & $14(10 \%)$ & $8(9 \%)$ & $6(11 \%)$ & $6(15 \%)$ & $8(8 \%)$ & $3(4 \%)$ & $11(15 \%)$ \\
\hline
\end{tabular}

Proportion $\geq 50 \%$ were considered common coping strategies among diabetes patients

Although there were differences in the use of coping strategies between type 1 and type 2 diabetes individuals, adolescents and adults, and females and males, most of these differences were not statistically significant except for religion between adults [70\% $(6.00 \pm 1.90)]$ and adolescents [53\% (5.18 \pm 2.50$)]$. The other coping strategy that was statistically significant was the use of self-blame with $11 \%(2.75 \pm 2.53)$ of adolescents vs $5 \%(1.96 \pm 1.97)$ of adults reporting using (see Table 3 ). 
Table 3

Mean differences of patient characteristic on different coping strategies

\begin{tabular}{|c|c|c|c|c|c|c|c|c|c|c|}
\hline \multicolumn{2}{|c|}{ Coping strategy } & \multicolumn{2}{|c|}{$\begin{array}{l}\text { Type of } \\
\text { Diabetes }\end{array}$} & \multirow{2}{*}{$\begin{array}{l}P \\
\text { Value }\end{array}$} & \multicolumn{2}{|l|}{ Age Category } & \multirow{2}{*}{$\begin{array}{l}P \\
\text { Value }\end{array}$} & \multicolumn{2}{|l|}{ Sex } & \multirow{2}{*}{$\begin{array}{l}P \\
\text { Value }\end{array}$} \\
\hline & & T1D & T2D & & Adolescents & Adults & & Males & Females & \\
\hline \multirow[t]{2}{*}{ Brief cope } & $\mathrm{M}$ & 53.40 & 57.18 & \multirow{2}{*}{ > } & 50.65 & 55.95 & \multirow{2}{*}{0.05} & 56.15 & 53.40 & \multirow{2}{*}{0.05} \\
\hline & SD & 15.96 & 13.77 & & 16.65 & 14.39 & & 17.09 & 12.47 & \\
\hline \multirow[t]{2}{*}{$\begin{array}{l}\text { Behavioural } \\
\text { strategies }\end{array}$} & $M$ & 27.10 & 29.20 & $\overrightarrow{0.05}$ & 24.21 & 29.13 & \multirow[t]{2}{*}{$\begin{array}{l}< \\
0.01\end{array}$} & 29.79 & 26.30 & \multirow[t]{2}{*}{0.05} \\
\hline & SD & 9.47 & 9.52 & & 9.61 & 9.08 & & 10.48 & 7.88 & \\
\hline \multirow[t]{2}{*}{$\begin{array}{l}\text { Emotional } \\
\text { strategies }\end{array}$} & $M$ & 25.60 & 28.09 & $\begin{array}{l}<.05 \\
0.05\end{array}$ & 25.29 & 26.67 & \multirow[t]{2}{*}{$\begin{array}{l}> \\
0.05\end{array}$} & 26.25 & 26.48 & \multirow[t]{2}{*}{0.05} \\
\hline & SD & 8.03 & 6.30 & & 8.76 & 7.11 & & 8.06 & 6.94 & \\
\hline \multicolumn{11}{|c|}{ Adaptive coping strategies } \\
\hline \multirow{2}{*}{$\begin{array}{l}\text { Active } \\
\text { coping }\end{array}$} & $M$ & 5.31 & 5.44 & \multirow{2}{*}{$\begin{array}{l}> \\
0.05\end{array}$} & 4.85 & 5.55 & \multirow{2}{*}{$\overrightarrow{0.05}$} & 5.63 & 5.12 & \multirow{2}{*}{ > 0.05} \\
\hline & SD & 2.20 & 1.99 & & 2.28 & 2.03 & & 2.07 & 2.15 & \\
\hline \multirow{2}{*}{$\begin{array}{l}\text { Emotional } \\
\text { support }\end{array}$} & M & 4.48 & 4.95 & \multirow{2}{*}{$\overrightarrow{0.05}$} & 4.41 & 4.76 & \multirow{2}{*}{$\overrightarrow{0.05}$} & 4.91 & 4.49 & \multirow{2}{*}{ P.05 } \\
\hline & SD & 2.13 & 2.27 & & 2.31 & 2.21 & & 2.11 & 2.32 & \\
\hline \multirow[t]{2}{*}{$\begin{array}{l}\text { Instrumental } \\
\text { support }\end{array}$} & $M$ & 5.24 & 5.74 & $\begin{array}{l}> \\
0.05\end{array}$ & 5.20 & 5.54 & $\overrightarrow{0.05}$ & 5.40 & 5.51 & $\begin{array}{l}> \\
0.05\end{array}$ \\
\hline & SD & 2.13 & 2.27 & & 2.31 & 2.21 & & 2.11 & 2.32 & \\
\hline \multirow[t]{2}{*}{$\begin{array}{l}\text { Positive } \\
\text { reframing }\end{array}$} & $M$ & 3.98 & 4.17 & $\overrightarrow{0.05}$ & 3.45 & 4.33 & $\overrightarrow{0.05}$ & 4.28 & 3.96 & $\begin{array}{l}> \\
0.05\end{array}$ \\
\hline & SD & 2.29 & 2.26 & & 2.19 & 2.30 & & 2.42 & 2.18 & \\
\hline \multirow[t]{2}{*}{ Planning } & $M$ & 4.61 & 4.91 & $\overrightarrow{0.05}$ & 4.15 & 4.96 & $\overrightarrow{0.05}$ & 5.02 & 4.49 & $\overrightarrow{0.05}$ \\
\hline & SD & 2.31 & 2.35 & & 2.55 & 2.26 & & 2.35 & 2.34 & \\
\hline \multirow[t]{2}{*}{ Acceptance } & $M$ & 5.76 & 5.61 & $\overrightarrow{0.05}$ & 5.72 & 5.70 & $\overrightarrow{0} 0.05$ & 5.75 & 5.63 & $\overrightarrow{0.05}$ \\
\hline & SD & 2.03 & 2.11 & & 2.21 & 2.03 & & 1.97 & 2.17 & \\
\hline \multirow[t]{2}{*}{ Religion } & $M$ & 5.60 & 6.03 & $\overrightarrow{0.05}$ & 5.18 & 6.00 & $<.05$ & 5.46 & 6.09 & $\overrightarrow{0.05}$ \\
\hline & SD & 2.13 & 1.98 & & 2.50 & 1.90 & & 2.20 & 1.93 & \\
\hline $\begin{array}{l}\text { Maladaptive } \\
\text { strategies }\end{array}$ & ping & & & & & & & & & \\
\hline Denial & $M$ & 2.76 & 3.29 & $>$ & 2.54 & 3.05 & $>$ & 2.85 & 3.01 & $>$ \\
\hline & SD & 2.40 & 2.45 & & 2.46 & 2.45 & & 2.51 & 2.40 & \\
\hline
\end{tabular}




\begin{tabular}{|c|c|c|c|c|c|c|c|c|c|c|}
\hline \multicolumn{2}{|c|}{ Coping strategy } & \multicolumn{2}{|c|}{$\begin{array}{l}\text { Type of } \\
\text { Diabetes }\end{array}$} & \multirow{2}{*}{$\begin{array}{l}P \\
\text { Value }\end{array}$} & \multicolumn{2}{|l|}{ Age Category } & \multirow{2}{*}{$\begin{array}{l}P \\
\text { Value }\end{array}$} & \multicolumn{2}{|l|}{ Sex } & \multirow{2}{*}{$\begin{array}{l}P \\
\text { Value }\end{array}$} \\
\hline & & T1D & T2D & & Adolescents & Adults & & Males & Females & \\
\hline \multirow{2}{*}{$\begin{array}{l}\text { Substance } \\
\text { use }\end{array}$} & M & 0.91 & 0.81 & \multirow{2}{*}{$\vec{D}_{0.05}$} & 0.73 & 0.92 & \multirow{2}{*}{$>_{0.05}$} & 1.10 & 0.66 & \multirow{2}{*}{$\begin{array}{l}> \\
0.05\end{array}$} \\
\hline & SD & 1.90 & 1.72 & & 1.96 & 1.77 & & 2.07 & 1.53 & \\
\hline \multirow{2}{*}{$\begin{array}{l}\text { Behavioural } \\
\text { disengage }\end{array}$} & $M$ & 2.95 & 3.09 & \multirow{2}{*}{$\overrightarrow{0} .05$} & 3.67 & 3.04 & \multirow{2}{*}{$\overrightarrow{0.05}$} & 3.11 & 2.79 & \multirow{2}{*}{$\begin{array}{l}> \\
0.05\end{array}$} \\
\hline & SD & 2.39 & 2.38 & & 2.31 & 2.41 & & 2.68 & 2.09 & \\
\hline \multirow[t]{2}{*}{ Venting } & M & 3.26 & 3.53 & \multirow{2}{*}{$\begin{array}{l}> \\
0.05\end{array}$} & 3.40 & 3.23 & \multirow{2}{*}{$>_{0.05}$} & 3.18 & 3.37 & \multirow{2}{*}{$\begin{array}{l}> \\
0.05\end{array}$} \\
\hline & SD & 2.45 & 2.08 & & 2.63 & 2.21 & & 2.29 & 2.39 & \\
\hline \multirow[t]{2}{*}{ Humour } & M & 1.90 & 1.62 & \multirow{2}{*}{$\vec{D}_{0.05}$} & 1.95 & 1.67 & \multirow{2}{*}{$\begin{array}{l}> \\
0.05\end{array}$} & 1.55 & 1.97 & \multirow{2}{*}{$\overrightarrow{0} 0.05$} \\
\hline & SD & 2.15 & 2.09 & & 2.56 & 1.91 & & 1.86 & 2.33 & \\
\hline \multirow[t]{2}{*}{ Self-blame } & $M$ & 2.44 & 1.90 & \multirow{2}{*}{$\overrightarrow{0} 05$} & 2.73 & 1.96 & \multirow{2}{*}{$\hat{0.05}$} & 2.16 & 2.08 & \multirow{2}{*}{$\vec{l}_{0.05}$} \\
\hline & SD & 2.34 & 1.81 & & 2.53 & 1.97 & & 1.91 & 2.28 & \\
\hline
\end{tabular}

Overall, Zambian individuals with diabetes reported using more behavioural focused strategies $20.08 \pm 9.28$ than emotional strategies $26.60 \pm 7.46(t=2.25, \mathrm{df}=106, \mathrm{p}<0.05)$. Among adult people, behavioural strategies were more used $29.13 \pm 9.08$ compared to emotional strategies $26.67 \pm 7.11(t=2.88$, df $82,<0.01)$ while for adolescents, emotional strategies were more likely to be used $(25.29 \pm 8.76)$ compared to behavioural strategies (24.21 \pm 9.61$)$. However, these differences were not statistically significant, $t=-0.78, \mathrm{df}, 23, p>0.05$. Regarding the type of diabetes, behavioural strategies were likely to be used $27.10 \pm 9.47$ compared to emotional $25.60 \pm 8.03$ among individuals with type 1 diabetes, although this difference was not statistically significant $t=1.66, \mathrm{df}=57, p$ $>0.05$. For type 2 diabetes, behaviour strategies were more likely to be used $29.20 \pm 9.52$ compared to emotional strategies $28.09 \pm 6.30$, although this difference was also not statistically significant. For males, behaviour strategies were more likely to be used $29.79 \pm 10.48$ compared to emotional strategies $26.25 \pm 8.06$ and this difference was statistically significant $t=2.16, \mathrm{df}=52, p<0.01$. For females, there was no difference in the use of behavioural strategies $(26.30 \pm 7.88)$ and emotional strategies $26.48 \pm 6.94), t=-0.20, \mathrm{df}=53, p>0.05$.

Correlations between coping strategies, diabetes emotional distress, depression and diabetes self-care are presented in Table 4. Results showed that use of behavioural focused strategies was associated with increased report of diabetes emotional distress $(r=0.430, p<0.001)$, and high use of emotional focused strategies was also associated with increase report of emotional distress $(r=0.374, P<0.001)$ and with increased report of depressive symptoms $(r=0.475, p<0.001)$.

Adaptive coping strategies including active coping $(r=0.247, p<0.01)$ and positive reframing $(r=0.278, p<0.01)$ were associated with increased emotional distress while use of emotional support was only associated with improved diabetes self-care $(r=0.263, p<0.01)$.

Maladaptive coping strategies including self-distraction $(r=0.370, p<0.001)$; behavioural disengagement $(r=$ $0.448, p<0.001)$; denial $(r=0.402, p<0.001)$; substance use $(r=0.193, p<0.05)$; humour $(r=0.173, p<0.05)$; selfblame $(r=0.238, p<0.01)$ and; venting $(r=0.326, p<0.001)$ were associated with increased emotional distress. In addition, Denial $(r=0.191, p<0.05)$; substance use $(r=0.177, p<0.05)$; self-blame $(r=0.230, p<0.01)$ and; venting 
$(r=0.206, p<0.05)$ were associated with increased depressive symptoms. Furthermore, use of self-blame $(r=$ $-0.171, p<0.05)$ was associated with poor diabetes self-care.

Table 4

Correlation matrix for coping strategies, diabetes emotional distress, depression and diabetes selfcare

\begin{tabular}{|c|c|c|c|}
\hline & Diabetes Specific Emotion Distress & Depression & Self-Care \\
\hline Brief Cope (Total Score) & $0.475^{\star \star \star}$ & $0.246 *$ & 0.007 \\
\hline Behavioural focused & $0.430 * \star \star$ & 0.175 & 0.062 \\
\hline Emotional focused & $0.374 * \star \star$ & $0.321 * \star$ & 0.003 \\
\hline \multicolumn{4}{|l|}{ Adaptive coping strategies } \\
\hline Active coping & $0.247 * \star$ & 0.108 & 0.078 \\
\hline Use of emotional support & 0.079 & 0.141 & $0.263^{* \star}$ \\
\hline Use of instrumental support & 0.159 & -0.039 & 0.118 \\
\hline Positive reframing & $0.278 * \star$ & 0.142 & 0.104 \\
\hline Planning & 0.120 & -0.001 & -0.017 \\
\hline Acceptance & -0.053 & 0.003 & -0.016 \\
\hline Religion & 0.122 & 0.102 & 0.129 \\
\hline \multicolumn{4}{|l|}{ Maladaptive coping strategies } \\
\hline Self-blame & $0.238 * *$ & 0.150 & $-0.171 *$ \\
\hline Self- distraction & $0.370 * \star \star$ & 0.137 & 0.017 \\
\hline Denial & $0.402^{* \star *}$ & $0.191 *$ & -0.071 \\
\hline Substance use & $0.193 *$ & $0.177^{*}$ & -0.066 \\
\hline Behavioural disengagement & $0.448 * * *$ & 0.170 & -0.023 \\
\hline Venting & $0.326 * \star \star$ & $0.206 *$ & 0.068 \\
\hline \multirow[t]{2}{*}{ Humour } & $0.173 *$ & $0.230 * *$ & -0.016 \\
\hline & ${ }^{\star} p=<0.05$ & $\star \star p=<0.01$ & $\star \star * \star p=<0.001$ \\
\hline
\end{tabular}

\section{Discussion}

This study aimed to identify coping strategies mostly used among individuals with diabetes in Zambia and examine how these strategies are associated with diabetes-related emotional distress, depression, and diabetes self-care. This study showed that the most frequently used coping strategies were religion, active coping, instrumental use and acceptance. These strategies are considered adaptive in light of people with chronic diseases such as diabetes and non-clinical samples. These findings are similar to a Turkish study of type 1 and 2 diabetes except for active coping. The differences included positive reframing, self-distraction, and venting common in a 
Turkish [6] than the Zambian sample. These findings could be different from people in Western developed countries.

The highest proportion of individuals used religious coping. Zambia is a very religious country. Therefore, most Christians hope God to heal them or ameliorate their suffering by relying on inner strength to keep them going with hope, similar to findings in Iran [31]. Consistent with other chronic illnesses such as HIV, there are reports of individuals relying on inner strength supplied by their Christian faith to cope with HIV [32].

Although religion was the most frequently used coping strategy, it was not associated with diabetes emotional distress, depression and diabetes self-care. Our findings contrast with a sample of Nigerian individuals with diabetes whose high intrinsic and extrinsic religiosities were associated with positive coping skills and better treatment outcomes in people with depression or diabetes [33]. The Nigerian findings confirm that religion is an adaptive coping strategy for diabetes. In our study, we only found a significant difference in the use of religion as a coping strategy between adolescents and adults. This finding is consistent with the trends worldwide that shows that young people are less religious than adults [34].

In addition to frequently using adaptive coping strategies, Zambian individuals with diabetes were more likely to use behavioural than emotional strategies. Behavioural coping strategies are overt physical activities aimed at removing or averting the stressor. In contrast, emotion strategies aim to reduce and manage the intensity of the negative and distressing emotions caused by a stressful situation rather than solving the problematic situation itself [35]. Thus, emotional strategies make a person feel better but don't solve the source of one's distress. Emotional focused coping often gets utilised when the problem is out of control or in situations where the stressor is unavoidable e.g., having a chronic and terminal illness or sudden death, and one needs to cope and accept the situation [35]. Furthermore, adults and males were more likely to use behavioural strategies, although this difference was not statistically significant.

Mixed results were found regarding the association between coping strategies and emotional distress, depression and self-care. Although individuals with diabetes used adaptive coping strategies more than maladaptive, most of them were not associated with psychological outcomes except for active coping and emotional support. Adaptive coping strategies confront problems directly, make practically realistic evaluations of problems, recognise and change unhealthy emotional reactions, and prevent adverse effects on the body. Surprisingly, active coping where one is intentionally or is goal-directed to minimise the physical, psychological or social stressor was associated with increased diabetes distress. It could be that some of the stressors, such as deprivation of food or being overwhelmed with diabetes regimens, cannot be removed because they are beyond their capabilities. It can be exasperating to actively cope with what one cannot change (or reduce) given the high poverty and weak health system these people find themselves in. This could explain why many individuals use emotional focused coping, which gets utilised when the problem is out of one's control. A person needs to cope and accept the situation beyond their capability.

Regarding diabetes self-care, only emotional support was associated with better diabetes care. Emotional and psychological support has been documented to improve people's ability to adjust or take adequate responsibility in diabetes self-management [36]. In chronic illnesses such as diabetes, emotional support is considered an adaptive coping strategy. Specifically, it positively impacts a healthy diet, increased perceived support, higher self-efficacy, improved psychological well-being, and better glycaemic control, according to data from a recent systematic review [37]. 
As expected, most maladaptive coping strategies were associated with negative outcomes. For instance, some scales within behavioural focus such as self-distraction, substance use, and behavioural disengagement were associated with increased emotional distress because they all temporary address the stressor. These do not take the problem away. For example, with behavioural disengagement, individuals reduce their efforts to deal with the stressor, which maintains or increases diabetes emotional distress. Further, emotionally focused strategies were associated with increased emotional distress. This domain is a facet that has several maladaptive strategies such as denial, venting, humour which could worsen emotional distress. Therefore, it was not surprising that self-blame, humour, venting, and denial were associated with increased emotional distress. For instance, a systematic review found that self-blame is associated with increased distress [38]. Generally, our data is similar to the Turkish data that showed that problem-focused and emotional-focused strategies were used in both type 1 and type 2 diabetes [6].

Furthermore, denial, substance use, venting, self-distraction, and humour increased depressive symptoms. About $18 \%$ (14\% type 1 and 22\% type 2) used denial. Refusing to accept a problem or reality can interfere with one's ability to tackle challenges simply because one cannot acknowledge the problem and downplay consequences which can, in the long run, increase anxiety if the problem is not going away. Moreover, people with depression in stressful situations often use strategies based on denial and avoidance and have more difficulties finding positive aspects of stressful events [39]. With regard to substance use, our study is consistent with findings of metaanalysis studies that have shown that depression is associated with concurrent alcohol use, drug use and impairment in clinical and community samples $[40,41]$. Although the percentage of users was small, more education is needed. Only $3 \%$ (3\% type 1 and $3 \%$ type 2 ) used this strategy. Humour was associated with increased depressive symptoms. About 10\% (9\% type 1 and 11\% type 2 ) used this strategy. One possible explanation for this association is that humour is likely to increase depression if it is targeted at mocking a stressor, simply because humour works well as a coping strategy if the event or interaction is pleasurable [42]. Our findings are consistent with Kuiper and colleagues who showed that the maladaptive components of humour that are self-focused (e.g., self-defeating and belaboured humour) predict detrimental effects on poorer self-esteem, greater depression and anxiety [43]. As with self-distraction, it was expected that this relationship would be observed.

Distracting oneself from a stressor is a temporal solution because the stressor does not go away with this strategy. Therefore, by temporarily distracting yourself, you may give the emotion some time to decrease in intensity, but it will still emerge later, which can be depressing. We observed that a good percentage of our sample utilises this strategy (35\% [32\% type 1 and 37\% type). This observation is consistent with our initial qualitative study, which showed adolescents used distraction as a coping strategy [21]. Thus, our current study validates this study.

Venting was also associated with increased depressive symptoms. About 19\% (22\% type 1 and $15 \%$ type 2 ) used this strategy. Venting refers to stating unpleasant feelings or expressing one's negative feelings (Carver 1997) [23] and is a maladaptive strategy. This coping strategy is similar to the explosiveness of speech, one of the types $A$ behaviour pattern characteristics. The Type A behaviour pattern is another response to a stressor characterised by extreme hostility, competitiveness, hurry, impatience, restlessness, aggressiveness, and explosiveness of speech (Ito \& Matsushima 2017) [44]. This kind of behaviour is likely to increase sadness and loneliness, precursors of depression. Self-blame was associated with reduced diabetes self-care. Self-blame has been associated with negative health outcomes (Harry 2018) [45]. As observed earlier, self-blame is related to distress, affecting diabetes self-care $[10,46]$. This is because self-criticism/blame is associated with low resilience to adhere to diabetes care [47] hence considered a maladaptive coping strategy.

Page $11 / 16$ 
All coping scales (total score) was related to increased emotional distress and increased depressive symptoms. This finding remains unclear why. However, it could be that using multiple coping strategies can be frustrating when a person has not mastered the ones that work well for them, hence the increase in experience of diabetesrelated stress and depressive symptoms. Consequently, using multiple styles that a person does not find effective may lead pessimistic outlook on finding a solution [48]. One has to identify what works to be consistently used and produce results. Using multiple coping strategies can lead to trouble organising thoughts on what works and does not work and may lead individuals to keep switching strategies to find what work. This process may be frustrating and increase emotional distress.

Moreover, emotional oriented coping appears to play a role in developing depressive symptoms, anxiety and diabetes-related distress [49]. Equally, behavioural-focused strategies were associated with increased experience of emotional distress. Again, we believe that individuals using behavioural focused strategies apply coping flexibility (i.e., an individual's ability to modify and change coping strategies depending on the context). The availability of numerous coping strategies may be an important precursor to coping flexibility. Coping flexibility can only be exercised if an individual can access and use different coping strategies [50] but may be ineffective if they do not master the strategies that work for them.

This study has some limitations. Firstly, we did not have data on diabetes biological markers such as HbA1c and specific medication the people were using. Secondly, our sample size was small. However, this study compared strategies used between type 1 and type 2 people, which most studies tend to report separately, making it difficult to make comparisons. Further, to the author's best knowledge, this is the first study to investigate coping strategies that people with diabetes use in Zambia. Thus, this data on different coping strategies used between different age groups, types of diabetes, sex, and how they are used on different psychological challenges they face may be important for diabetes care and education in Zambia and other Sub Saharan African countries.

\section{Conclusion}

In conclusion, adaptive coping strategies such as religion, acceptance, instrumental support and active coping are the most frequently used coping strategies among Zambian individuals with diabetes. The difference only lay in the use of religion, with more adults likely to use it as a coping strategy. Mixed results were found on the use of coping strategies and how they are associated with diabetes-specific emotional distress, depression and diabetes self-care. Many people used maladaptive coping strategies that affected their psychological well-being and diabetes management. There is a need to help people use more behavioural but adaptive strategies in order to improve their quality of life.

\section{Abbreviations}

Brief COPE - Brief Coping Orientation to Problems Experienced; HIV -Human Immunodeficiency Virus; LMIC - Lowand middle-income country; MDI - Major Depression Inventory; PAID - Problem Areas in Diabetes; PWD - People with Diabetes; SCI - Self Care Inventory; T1DM -Type 1 Diabetes Mellitus; T2DM -Type 2 Diabetes Mellitus

\section{Declarations}

Acknowledgement: The author would like to thank all the participants for actively participating in this study, and the staff at the University Teaching Hospital.

Page 12/16 
Authors' contribution: GH collected data, analysed and wrote the manuscript.

Funding: The author discloses receipt of the ISSBD-JF mentored fellowship granted the author during PhD studies

Availability of data: The datasets used and/or analysed during the current study available from the

corresponding author on reasonable request. Data is not currently public because more analysis is still being conducted on the data set.

\section{Ethical approval and consent}

Informed consent for participants above 18 years and assent following informed consent from guardians for participants below 18 years was obtained. All procedures performed in studies involving human participants adhered to the ethical standards of the institutional and/or national research committee and with the 1964 Helsinki declaration and its later amendments or comparable ethical standards. The ethics committee of the School of Humanities and Social Sciences, University of Zambia, approved the study on 29th April 2011 (Reference number IRB: 00006464, IORG: 005376).

Consent for publication: Not applicable

Competing interests: The author declared no potential financial and non-financial conflicts of interest concerning this article's research, authorship, and publication.

\section{Author details:}

University of Zambia, School of Humanities and Social Sciences, Department of Psychology, Lusaka, Zambia

\section{References}

1. Chan J, DeMelo M, Gingras J, Gucciardi E. Challenges of diabetes self-management in adults affected by food insecurity in a large urban centre of Ontario, Canada. International journal of endocrinology. 2015 Jan 1; 2015.

2. Debussche X, Balcou-Debussche M, Besançon S, Traore SA. Challenges to diabetes self-management in developing countries. Diabetes Voice. 2009; 54(Special Issue):12-4.

3. Pastakia SD, Pekny CR, Manyara SM, Fischer L. Diabetes in sub-Saharan Africa-from policy to practice to progress: targeting the existing gaps for future care for diabetes. Diabetes, metabolic syndrome and obesity: targets and therapy. 2017; 10:247.

4. Hilliard ME, De Wit M, Wasserman RM, Butler AM, Evans M, Weissberg-Benchell J, Anderson BJ. Screening and support for emotional burdens of youth with type 1 diabetes: strategies for diabetes care providers. Pediatric diabetes. 2018 May; 19(3):534-43.

5. Sumlin LL, Garcia TJ, Brown SA, Winter MA, Garcia AA, Brown A, Cuevas HE. Depression and adherence to lifestyle changes in type 2 diabetes: a systematic review. The Diabetes Educator. 2014 Nov; 40(6):731-44.

6. Tuncay T, Musabak I, Gok DE, Kutlu M. The relationship between anxiety, coping strategies and characteristics of patients with diabetes. Health and quality of life outcomes. 2008 Dec; 6(1):1-9.

7. McCoy MA, Theeke LA. A systematic review of the relationships among psychosocial factors and coping in adults with type 2 diabetes mellitus. International journal of nursing sciences. 2019 Oct 10; 6(4):468-77. 
8. Young-Hyman D, De Groot M, Hill-Briggs F, Gonzalez JS, Hood K, Peyrot M. Psychosocial care for people with diabetes: a position statement of the American Diabetes Association. Diabetes care. 2016 Dec 1; 39(12):2126-40.

9. Roy T, Lloyd CE. Epidemiology of depression and diabetes: a systematic review. Journal of affective disorders. 2012 Oct $1 ; 142:$ S8-21.

10. Hapunda G, Abubakar A, Pouwer F, Van de Vijver F. Validity and reliability of the Zambian version of the Problem Areas in Diabetes (PAID) scale: a triangulation with cognitive interviews. South African Journal of Diabetes and Vascular Disease. 2016 Jul 1; 13(1):4-12.

11. Hema DA, Roper SO, Nehring JW, Call A, Mandleco BL, Dyches TT. Daily stressors and coping responses of children and adolescents with type 1 diabetes. Child: care, health and development. 2009 May; 35(3):330-9.

12. Malipa MN, Menon JA. The relationship between compliance and quality of life among adolescents with diabetes mellitus type1. Medical Journal of Zambia. 2013; 40(3):93-103.

13. Albai A, Sima A, Papava I, Roman D, Andor B, Gafencu M. Association between coping mechanisms and adherence to diabetes-related self-care activities: a cross-sectional study. Patient preference and adherence. 2017; 11:1235.

14. Grey M. Coping skills training for youths with diabetes. Diabetes Spectrum. 2011 May 1; 24(2):70-5.

15. Lloyd CE, Nouwen A, Sartorius N, Ahmed HU, Alvarez A, Bahendeka S, Basangwa D, Bobrov AE, Boden S, Bulgari V, Burti L. Prevalence and correlates of depressive disorders in people with Type 2 diabetes: results from the International Prevalence and Treatment of Diabetes and Depression (INTERPRET-DD) study, a collaborative study carried out in 14 countries. Diabetic Medicine. 2018 Jun; 35(6):760-9.

16. Clay, R.A. More is needed to treat diabetes. Monitor on Psychology, 2017 Jun: 48(6), 36

17. Brannon L, Feist J. Introduction to health psychology. India Edition, Thompson Wadsworth. 2007; 9:111 - 35.

18. Kirby R, Shakespeare-Finch J, Palk G. Adaptive and maladaptive coping strategies predict posttrauma outcomes in ambulance personnel. Traumatology. $2011 \mathrm{Dec} ; 17(4): 25-34$.

19. Knowles SR, Apputhurai P, O’Brien CL, Ski CF, Thompson DR, Castle DJ. Exploring the relationships between illness perceptions, self-efficacy, coping strategies, psychological distress and quality of life in a cohort of adults with diabetes mellitus. Psychology, health \& medicine. 2020 Feb 7; 25(2):214-28.

20. Yasui-Furukori N, Murakami H, Otaka H, Nakayama H, Murabayashi M, Mizushiri S, Matsumura K, Tanabe J, Matsuhashi Y, Yanagimachi M, Nakamura K. Coping behaviors and depressive status in individuals with type 2 diabetes mellitus. Annals of general psychiatry. 2019 Dec; 18(1):1-8.

21. Hapunda G, Abubakar A, Van de Vijver F, Pouwer F. Living with type 1 diabetes is challenging for Zambian adolescents: qualitative data on stress, coping with stress and quality of care and life. BMC endocrine disorders. $2015 \mathrm{Dec} ;$ 15(1):1-2.

22. Waugh CE, Shing EZ, Furr RM. Not all disengagement coping strategies are created equal: positive distraction, but not avoidance, can be an adaptive coping strategy for chronic life stressors. Anxiety, Stress, \& Coping. 2020 Sep 2; 33(5):511-29.

23. Carver CS. You want to measure coping but your protocol'too long: Consider the brief cope. International journal of behavioral medicine. 1997 Mar; 4(1):92-100.

24. Snell DL, Siegert RJ, Hay-Smith EJ, Surgenor LJ. Factor structure of the Brief COPE in people with mild traumatic brain injury. The Journal of head trauma rehabilitation. 2011 Nov 1; 26(6):468-77. 
25. Yusoff N, Low WY, Yip CH. Reliability and validity of the Brief COPE Scale (English version) among women with breast cancer undergoing treatment of adjuvant chemotherapy: a Malaysian study. Medical Journal of Malaysia. 2010; 65(1):41-4.

26. Welch GW, Jacobson AM, Polonsky WH. The Problem Areas in Diabetes Scale: an evaluation of its clinical utility. Diabetes care. 1997 May 1; 20(5):760-6.

27. Weissberg-Benchell J, Antisdel-Lomaglio J. Diabetes-specific emotional distress among adolescents: feasibility, reliability, and validity of the problem areas in diabetes-teen version. Pediatric diabetes. 2011 Jun; 12(4pt1):341-4.

28. Weinger K, Butler HA, Welch GW, La Greca AM. Measuring diabetes self-care: a psychometric analysis of the Self-Care Inventory-Revised with adults. Diabetes care. 2005 Jun 1;28(6):1346-52.

29. Bech P, Rasmussen NA, Olsen LR, Noerholm V, Abildgaard W. The sensitivity and specificity of the Major Depression Inventory, using the Present State Examination as the index of diagnostic validity. Journal of affective disorders. 2001 Oct 1; 66(2-3):159-64.

30. Cuijper P, Dekker J, Noteboom A, Smit N, Peen J. The sensitivity and specificity of the Major Depression Inventory in outpatients. BMC Psychiatry, 2007; 7(39). doi.org/10.1186/1471-244X-7-39.

31. Shamsalinia A, Pourghaznein T, Parsa M. The relationship between hope and religious coping among patients with type 2 diabetes. Global journal of health science. 2016 Jan; 8(1):208.

32. Chinouya M, O'Keefe E. God will look after us: Africans, HIV and religion in Milton Keynes. Diversity in Health and Social Care. 2005; 2(3):177-86.

33. Amadi KU, Uwakwe R, Odinka PC, Ndukuba AC, Muomah CR, Ohaeri JU. Religion, coping and outcome in outpatients with depression or diabetes mellitus. Acta Psychiatrica Scandinavica. 2016 Jun; 133(6):489-96.

34. Pew Research Centre; 2018. The Age Gap in Religion Around the World [Internet]. Washington DC. [Updated 2018; cited 2021 November 7]. Available from https://www.pewforum.org/2018/06/13/the-age-gap-in-religionaround-the-world/

35. Galor, S; 2012. Emotional coping strategies. [Internet]. Amsterdam. [Updated 2012; cited 2021 November 7]. Available from: https://drsharongalor.wordpress.com/2012/03/31/emotion-focused-coping-strategies/

36. Kalra S, Jena BN, Yeravdekar R. Emotional and psychological needs of people with diabetes. Indian journal of endocrinology and metabolism. 2018 Sep; 22(5):696.

37. Pamungkas RA, Chamroonsawasdi K, Vatanasomboon P. A systematic review: family support integrated with diabetes self-management among uncontrolled type II diabetes mellitus patients. Behavioral Sciences. 2017 Sep; 7(3):62.

38. Callebaut L, Molyneux P, Alexander T. The relationship between self-blame for the onset of a chronic physical health condition and emotional distress: A systematic literature review. Clinical psychology \& psychotherapy. 2017 Jul; 24(4):965-86.

39. Orzechowska A, Zajączkowska M, Talarowska M, Gałecki P. Depression and ways of coping with stress: A preliminary study. Medical science monitor: international medical journal of experimental and clinical research. 2013; 19:1050.

40. Conner KR, Pinquart M, Gamble SA. Meta-analysis of depression and substance use among individuals with alcohol use disorders. Journal of substance abuse treatment. 2009 Sep 1; 37(2):127-37.

41. Conner KR, Pinquart M, Duberstein PR. Meta-analysis of depression and substance use and impairment among intravenous drug users (IDUs). Addiction. 2008 Apr; 103(4):524-34. 
42. Nezlek JB, Derks P. Use of humor as a coping mechanism, psychological adjustment, and social interaction.

43. Kuiper NA, Grimshaw M, Leite C, Kirsh G. Humor is not always the best medicine: Specific components of sense of humor and psychological well-being.

44. Ito M, Matsushima E. Presentation of coping strategies associated with physical and mental health during health check-ups. Community mental health journal. 2017 Apr 1; 53(3):297-305.

45. Harry KM. The Cardiac Self-Blame Attributions scale as a predictor of physical and mental health outcomes in underrepresented patients with cardiovascular disease. University of Missouri-Kansas City; 2018.

46. Khan A, Choudhary P. Investigating the association between diabetes distress and self-management behaviors. Journal of diabetes science and technology. 2018 Nov; 12(6):1116-24.

47. Yi-Frazier JP, Yaptangco M, Semana S, Buscaino E, Thompson V, Cochrane K, Tabile M, Alving E, Rosenberg AR. The association of personal resilience with stress, coping, and diabetes outcomes in adolescents with type 1 diabetes: Variable-and person-focused approaches. Journal of health psychology. 2015 Sep; 20(9):1196206.

48. Sahler OJ, Carr JE. Coping strategies. In Developmental-behavioral pediatrics 2009 Jan 1 (pp. 491-496). WB Saunders.

49. Burns RJ, Deschênes SS, Schmitz N. Associations between coping strategies and mental health in individuals with type 2 diabetes: Prospective analyses. Health Psychology. 2016 Jan; 35(1):78.

50. Heffer T, Willoughby T. A count of coping strategies: A longitudinal study investigating an alternative method to understanding coping and adjustment. PloS one. 2017 Oct 5; 12(10):e0186057. 